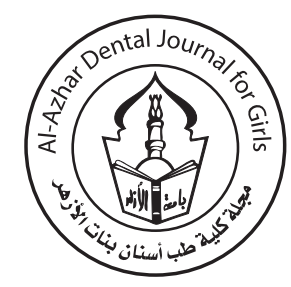

\title{
Clinical Performance and Remineralization Potential of Different Biomimitic Materials on White Spot Lesions
}

\author{
Raghda A. Kamh ${ }^{(1)}$, Maha A. Niazy ${ }^{(2)}$ and Mohamed A. El-Yasaky ${ }^{(3)}$
}

Codex : 41/1810

azhardentj@azhar.edu.eg

http://adjg.journals.ekb.eg

\section{KEYWORDS}

\section{Remineralization,}

White spot lesions,

Curodont repair, Remin Pro,

Polarized light microscope.

\begin{abstract}
Aim: This study was designed to evaluate and compare the re-mineralization potential of different biomimetic materials; self assembling peptide (P11-4), highly concentrated sodium fluoride agent and combination of fluoride, hydroxyapatite and xylitol paste on the white spot lesions. Materials and Methods: This study was conducted on 45 white spot lesions. Each white spot lesion was scored according to severity using the ICDAS II criteria, then assigned into three groups of 15 lesions each according to the re-mineralizing material used; Group A1: 15 lesions were treated with Self assembling peptide (P11-4) (curodont repair), Group A2: 15 lesions were treated with highly concentrated sodium fluoride agent (Lunos ${ }^{\circledR}$ Polierpaste Two in One), Group A3: 15 lesions were treated with fluoride, hydroxyapatite and xylitol paste (Remin Pro forte). Saliva $\mathrm{pH}$ was checked every month for three months using CRT buffer. Photographic records were taken before treatment and after treatment then after three months. Patients were recalled after 1 month, 2 months and 3 months of re- mineralizing agents' application. Data was presented as mean, median, standard deviation (SD). As most of the data was parametric, the differences between groups were evaluated by one way analysis of variance (ANOVA) test. This was followed by Tukey's post hoc test when ANOVA yielded positive results. The level of significance was set at $\mathrm{P}<0.05$. Results: the mean percentage change in ICDAS II scores improved for all the three re- mineralizing agents used as compared to baseline. No significant difference was noted at baseline $(\mathrm{p}=0.54)$. However, at 3 months the difference between groups was statistically significant, since most of the cases in Remin Pro group recorded score $1(66.6 \%)$, while most of the cases in Curodont and Lunos 2 in 1 group scored 2 (53.3\% and 80\% respectively). Score 0 recorded (20\%) for Remin Pro while $(13.3 \%)$ scored for Curodont. On the other hand, Lunos polier paste recorded no 0 score. According to Saliva buffer results; as a comparison between the three groups, $\mathrm{pH}$ of group (A3: Remin Pro forte) showed higher increase followed by group (A1: Curodont repair) then group (A2: Lunos polierpaste 2 in 1). Conclusions: All the tested materials have varying re-mineralization potential through Remin Pro forte was the most efficient. Self assembling peptides (P11-4) seem to believe in resisting the acid challenge. All agents were clinically efficient in management of white spot lesions.
\end{abstract}

Paper extracted from $\mathrm{PhD}$ thesis titled "Clinical Performance and Remineralization Potential of Different Biomimitic Materials on White Spot Lesions"

1. Associate Lecturer, Operative Dentistry Department, Sinai University

2. Professor and Head of Operative Dentistry Department, Faculty of Dental Medicine for Girls, Al- Azhar University.

3. Professor of Operative Dentistry Department, Dean of Faculty of Dental Medicine, Sinai University. 


\section{INTRODUCTION}

Dental caries is a multifactorial disease which has been a major public health problem for many centuries. The goal of modern dentistry is to manage non-cavitated caries lesions non- invasively through re-mineralization process to prevent the disease progression and improve aesthetics, strength, and function(1). Re-mineralization is defined as the process that supplies calcium, phosphate and fluoride ions from an external source to the tooth to convert ion deposition into crystal voids in demineralized enamel. Re-mineralization takes places at a higher $\mathrm{pH}$ of 7.5 to 8.5 in the presence of calcium and phosphate in the saliva among the enamel or dentine crystals re-crystalize. The calcium and phosphate come primarily from saliva and the mineral formed during re-mineralization is more resistant to acid than the original enamel or dentin mineral especially if fluoride is present to enhance re- mineralization and to be incorporated into the new crystals surfaces ${ }^{(2)}$.

Ideally, re-mineralizing agents need to rapidly precipitate on partially demineralized tooth structure and transform into a more stable, less acid-soluble apatite than the hard tissue replaced. The re-mineralization treatment depends on the caries clinical stage, the radiological extent of the lesion in enamel or dentin and the caries risk status of the patient, which determines the likelihood of the lesion progressing to cavitation (3).

The early process of enamel demineralization appears as a localized area of a milky lesion that can be found on the smooth surfaces of teeth which is called white spot lesion WSL ${ }^{(4)}$. Management of white spot lesion was depending on the role of fluoride in the form of fluoride mouthwashes, fluoride gels, fluoride toothpastes, fluoride varnishes, fluoride in bonding agents, and fluoride in dental resin composite ${ }^{(5)}$.

Recently, biomimetic approach to stabilize the calcium, phosphate and fluoride ions and to localize these ions in non-cavitated carious lesions for controlled re-mineralization shows a great promise for the non-invasive management of dental caries (6). One of the biomimetic re- mineralizing agents is self-assembling peptide (P11-4). The protective effect of self- assembling peptide (P11-4) (Curodont repair) and its efficacy in re-hardening whitespot lesion (WSL) produced by different acidic fluids through the oral cavity takes place for more investigation in dental field ${ }^{(7)}$.

Therefore, the present study aimed to evaluate and compare the re-mineralization potential of self assembling peptide (P11-4) (Curodont repair) that provides the non-invasive option for guided enamel regeneration versus highly concentrated sodium fluoride agent (Lunos polierpaste 2 in 1) and a paste from fluoride, hydroxyapatite, xylitol, ginger and curcuma combination in vivo (used for management of early carious lesions in enamel WSL).

\section{MATERIALS AND METHODS}

\section{Selection of the patients:}

This study was conducted on 45 white spot lesions. Patients were selected randomly from the restorative dentistry clinic at the faculty of dentistry, Girls branch, Al-Azhar University. Each patient was presented with 4 or more WSL. The objectives of the study were explained to all participants who signed an informed consent according to the guide of ethics committee of human research before starting the study. Each volunteer was selected according to the inclusion and exclusion criteria followed by Brunton et al ${ }^{(\mathbf{8})}$. Before scoring of white spot lesions dental prophylaxis was performed using prophylactic paste (Alpha-Pro prophylaxis paste, medium grit $29 \mu$, PM3995/REV003, Dental Technologies, Inc., USA) and bristle brushes (Prophy brush, oleland, China) before initial treatment and monthly before evaluation and scoring.

\section{Scoring of white spot lesions:}

Each white spot lesion was scored according to severity using the ICDAS II criteria ${ }^{(9)}$. For correct scoring all lesions were examined while surfaces were wet and dry ${ }^{(\mathbf{1 0}, 11)}$. 


\section{Patient risk assessment:}

Patients were assessed for their caries risk at the beginning of the study using caries risk assessment provided by the American Dental Association.

\section{Teeth Grouping:}

After examination, the lesions were assigned into three groups of 15 white spot lesions each according to the re-mineralizing material used. The first group (A1); 15 WSL were treated with Self assembling peptide (P11-4) (curodont repair, Credentis AG, Windisch, Switzerland). The second group (A2); 15 WSL were treated with highly concentrated sodium fluoride agent (Lunos® Polier paste Two in One, DÜRR DENTAL AG, Bietigheim- Bissingen, Germany). While the third group (A3); 15 WSL were treated with fluoride, hydroxyapatite and xylitol paste (Remin Pro forte, VOCO $\mathrm{GmbH}$, Cuxhaven, Germany).

\section{Application of the re-mineralizing agents:}

\section{Application of Curodont repair:}

Curodont repair was applied according to the manufacturer's instructions. Professional cleaning was performed to remove plaque, food debris and stains. Teeth were swapped using cotton $2 \%$ sodium hypochlorite for 20 seconds. Teeth were etched with $37 \%$ phosphoric acid (Dental Technologies, Inc., USA) for 20 seconds, rinsed with water and then dried. Curodont repair applicator unit was activated by pushing the two cylinders together. Single white spot lesion was treated by gently pressing the tip directly onto the tooth surface. Solution was allowed 5 minutes to diffuse and until the tooth surface appears dry. Eating, drinking and teeth brushing are possible directly after the treatment has been completed.

\section{Application of Lunos polier paste two in one:}

Lunos polier paste 2 in 1 was applied according to the manufacturer's instructions. Professional cleaning was performed to remove plaque, food debris and stains. Sufficient amount of paste was taken with spatula and filled into a dapping glass. One scope of Lunos polier paste 2 in 1 was applied on the white spot lesion and polished for 20 seconds until the polishing particles were broken down into fine particles and a soft creamy paste achieved. The paste was allowed on the white spot lesion surface for 5 minutes. Teeth were rinsed using water. Patient was advised to wait for 30 minutes after the treatment before eating or drinking.

\section{Application of Remin Pro forte:}

Remin Pro forte was applied according to the manufacturer's instructions. Professional cleaning was performed to remove plaque, food debris and stains. A ready-made bleaching tray was filled with Remin Pro forte and seated in the patient's mouth. The tray with the material was applied in the mouth for at least 3 minutes. Patient was advised to spit out the remaining amount after removal of the tray. Patient was advised to wait for 30 minutes after the treatment before eating or drinking.

\section{Assessment of teeth:}

\section{The International Caries Detection and Assessment System ICDAS II:}

A chart was made for each patient for follow up and scoring of the white spot lesions at different time periods. Patients were recalled after 1 month, 2 months and 3 months of re- mineralizing agents' application. They were previously instructed not to eat, drink or brush their teeth one hour before the appointment.

\section{Photographic records assessments:}

All photographic records were taken by a digital camera Lumix, Panasonic (DMC-FZ300, 1/2.3-inchMOS-Sensor, 4k Video,12.1 Megaixel, Leica DC Lens 24x F2.8 Optical Zoom, Panasonic, Osaka, Japan). Photographic records were taken before treatment and after three months. 


\section{Saliva buffer assessment:}

Saliva was collected to measure the change of $\mathrm{pH}$ every month for three months using CRT buffer (Ivoclar Vivadent clinical AG, Liechtenstein). CRT saliva buffer is a chair-side colour coded indicator for buffer saliva capacity and saliva $\mathrm{pH}$ that was used to inform the patient about the disadvantages of his dietary behaviour and educate him the importance of oral hygiene maintenance. The $\mathrm{pH}$ test was performed according to the manufacturer's instructions. Patient was instructed to sit upright. Saliva was stimulated by chewing a paraffin pellet and collected in a calibrated container over a defined period of 5 minutes with determined rate $1 \mathrm{ml} / \mathrm{min}$. The results were recorded at the baseline for each patient before the application of the re-mineralizing materials and repeated each month during the follow up period. Each patient had four records base line, after one month, after two months and after three months.

\section{Statistical analysis:}

Data was presented as mean, median, standard deviation (SD). Statistical analysis was performed using a commercially available software program SPSS 16 (Chicago, IL, USA) to compare the percent change in different stages. As most of the data was parametric, the differences between groups were evaluated by one way analysis of variance (ANOVA) test. This was followed by Tukey's post hoc test when ANOVA yielded positive results. The level of significance was set at $\mathrm{P}<0.05$.

\section{RESULTS}

\section{ICDAS II scores results}

\section{A-Changes in the ICDAS II scores within each group}

Statistical analysis revealed that the mean percentage ICDAS II score was improved for all groups treated using the three re-mineralizing agents (Curodont repair, Lunos polier paste 2 in 1 and Remin Pro) as compared to baseline.

In Curodont repair group, baseline scores recorded $33.3 \%$ for score 2 and $66.6 \%$ for score 3 . However at 3 months, the greatest percentage of cases recorded score $2(53.3 \%)$, followed by score $1(33.3 \%)$ and (13.3\%) for score 0. Chi square test revealed that this difference was statistically significant $(\mathrm{P}=0.0006)$ (Table 1) (Figure 1). In Lunos polier paste 2 in 1 group, baseline scores recorded (26.6\%) for score 2 and $(73.3 \%)$ for score 3 . However, at 3 months the greatest percentage of cases recorded score $2(80 \%)$, followed by score 1 (20\%). Chi square test revealed that this difference was statistically significant $(\mathrm{P}=0.0034) \quad$ (Table 1) (Figure 1). In Remin pro group, basic scores recorded (53.3\%) for score 2 and (46.6\%) for score 3 . However, at 3 months the greatest percentage of cases recorded score $1(66.6 \%)$, followed by $2(13.3 \%)$ and (20\%) for score 0. Chi square test revealed that this difference was statistically significant $(\mathrm{P}=0.0003)$ (Table 1).

\section{B-Changes in the ICDAS II scores between the three groups:}

Statistical analysis revealed that the mean percentage in ICDAS II scores improved for all the three re-mineralizing agents used (Curodont repair, Lunos polier paste 2 in 1 and Remin Pro) as compared to baseline.

On comparing the ICDAS II scores between the three treatments, no significant difference was noted at baseline $(\mathrm{p}=0.54)$. However, at 3 months the difference between groups was statistically significant, since most of the cases in Remin Pro group recorded score 1 (66.6\%), while most of the cases in Curodont repair and Lunos polier paste 2 in 1 group scored 2 (53.3\% and $80 \%$ respectively). Score 0 recorded (20\%) for Remin Pro while (13.3\%) scored for Curodont repair. On the other hand, Lunos polier paste 2 in 1 recorded no 0 score. (Table 1) 
Table (1): Number and percentage of clinical scores and significance of the difference within and between groups (chi square test):

\begin{tabular}{|c|c|c|c|c|c|c|c|c|c|c|}
\hline Materials & & & Basic & & & \multicolumn{2}{|c|}{3 months } & & $x^{2}$ & $\mathrm{P}^{\#}$ value \\
\hline & Score 0 & $\begin{array}{c}\text { Score } \\
1\end{array}$ & $\begin{array}{c}\text { Score } \\
2\end{array}$ & $\begin{array}{c}\text { Score } \\
3\end{array}$ & $\begin{array}{l}\text { Score } \\
0\end{array}$ & $\begin{array}{c}\text { Score } \\
1\end{array}$ & $\begin{array}{l}\text { Score } \\
2\end{array}$ & $\begin{array}{c}\text { Score } \\
3\end{array}$ & & \\
\hline $\begin{array}{l}\text { Curodont repair } \\
\qquad(\mathrm{n}=15)\end{array}$ & 0 & 0 & $\begin{array}{c}5 \\
(33.3 \%)\end{array}$ & $\begin{array}{c}10 \\
(66.6 \%)\end{array}$ & $\begin{array}{c}2 \\
(13.3 \%)\end{array}$ & $\begin{array}{c}5 \\
(33.3 \%)\end{array}$ & $\begin{array}{c}8 \\
(53.3 \%)\end{array}$ & 0 & 17.3 & $0.0006^{*}$ \\
\hline $\begin{array}{l}\text { Lunos polier paste } \\
\quad 2 \text { in } 1(n=15)\end{array}$ & 0 & 0 & $\begin{array}{c}4 \\
(26.6 \%)\end{array}$ & $\begin{array}{c}11 \\
(73.3 \%)\end{array}$ & 0 & $\begin{array}{c}3 \\
(20 \%)\end{array}$ & $\begin{array}{c}12 \\
(80 \%)\end{array}$ & 0 & 13.0 & $0.0034 *$ \\
\hline $\begin{array}{c}\text { Remin pro } \\
(\mathrm{n}=15)\end{array}$ & 0 & 0 & $\begin{array}{c}8 \\
(53.3 \%)\end{array}$ & $\begin{array}{c}7 \\
(46.6 \%)\end{array}$ & $\begin{array}{c}3 \\
(20 \%)\end{array}$ & $\begin{array}{c}10 \\
(66.6 \%)\end{array}$ & $\begin{array}{c}2 \\
(13.3 \%)\end{array}$ & 0 & 18.8 & $0.0003^{*}$ \\
\hline$x^{2}$ & \multicolumn{4}{|c|}{5.006} & \multicolumn{4}{|c|}{14.324} & ------ & \\
\hline $\mathrm{P}^{@}$ value & \multicolumn{4}{|c|}{$0.54 \mathrm{NS}$} & \multicolumn{4}{|c|}{$0.026^{*}$} & & \\
\hline
\end{tabular}

P\# value: significance of difference within the same group P@ value: significance of difference between groups Significance level $p<0.05, N S=$ non-significant, *significant

\section{Photographic records results}

\section{A-Changes in teeth treated with Curodont repair:}

Figure $(1, a)$ shows WSL on maxillary right and left central incisors at baseline recording score 3 according to the ICDAS II. While figure $(1, b)$ shows maxillary right and left central incisors after 3 months recording score 0 according to the ICDAS II.

\section{B-Changes in teeth treated with Lunos polier paste 2 in 1:}

Figure $(2$, a) are examples of clinically WSL (white arrows) on the labial surfaces of maxillary and mandibular right first and second premolars and mandibular right canine, with score 3 at baseline according to the ICDAS II. Figure $(2, b)$ show the range of response to a single application weekly for 3 months of Lunos polier paste 2 in 1 with time. All teeth recorded score 2 according to the ICDAS II.

\section{C-Changes in teeth treated with Remin Proforte}

Figure ( 3 , a and c) are examples of clinically WSL (white arrows) on the labial surfaces of maxillary right and left central incisors, left lateral incisor with score 3 while mandibular left lateral incisor scoring 1 , maxillary and mandibular left canine scoring 2 at baseline according to the ICDAS II. Figure $(3, \mathrm{~b}$ and d) show the range of response to a single application weekly for 3 months of Remin Pro forte with time. Figure $(3, b)$ WSL recorded score 2 for maxillary right central incisor, score 1 for left central incisor, while figure $(3, d)$ shows that the WSL scored 0 for the maxillary left lateral incisor and maxillary left canine as well as mandibular left lateral incisor score 0 , while the mandibular left canine recorded score1.

\section{Saliva buffer results}

In group (A1: Curodont repair) $\mathrm{pH}$ increased gradually by time from highly acidic before treatment to medium at the 1 st and 2 nd month, then low at 3rd month of the follow up period. In group (A2: Lunos polier paste 2 in 1) $\mathrm{pH}$ showed no difference by time through the treatment period. Records showed highly acidic $\mathrm{pH}$ before treatment and remained high at the 1 st month, $2^{\text {nd }}$ and $3^{\text {rd }}$ months of follow up period. In group (A3: Remin Pro forte) $\mathrm{pH}$ increased gradually by time from highly acidic before treatment to medium at the 1st month, then low at 2nd and 3rd months of follow up period.As a comparison between the three groups, $\mathrm{pH}$ of group (A3: Remin Pro forte) showed higher increase followed by group (A1: Curodont repair) then group (A2: Lunos polier paste 2 in 1). 


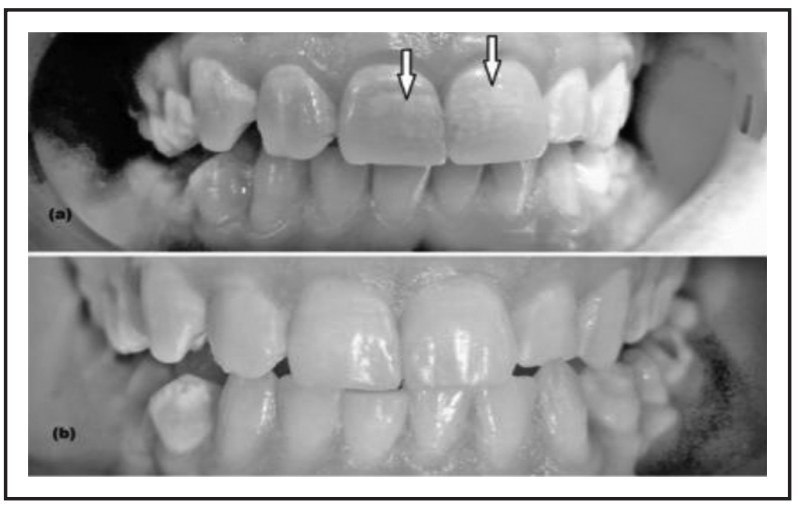

Fig. (1): Patient with white spot lesions (a) before tretment (b) after three months from Curodont repair treatment

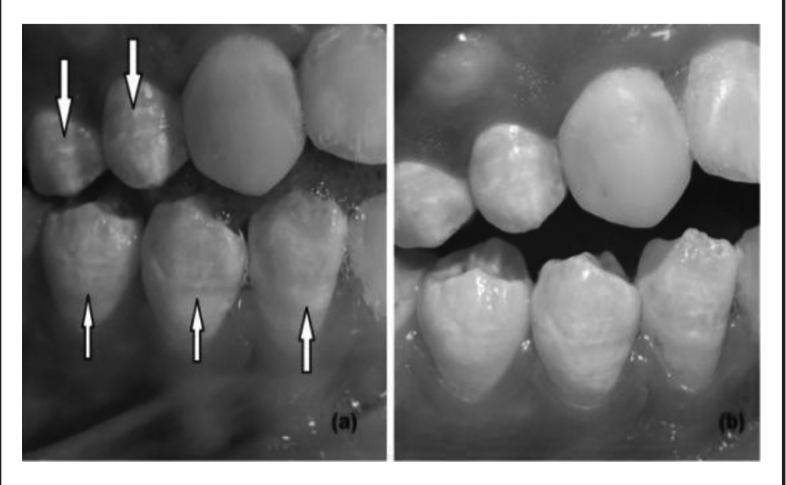

Fig. (2): Patient with white spot lesions (a and c) before tretment ( $b$ and $d$ ) after three months from Lunos polier paste 2 in 1 treatment

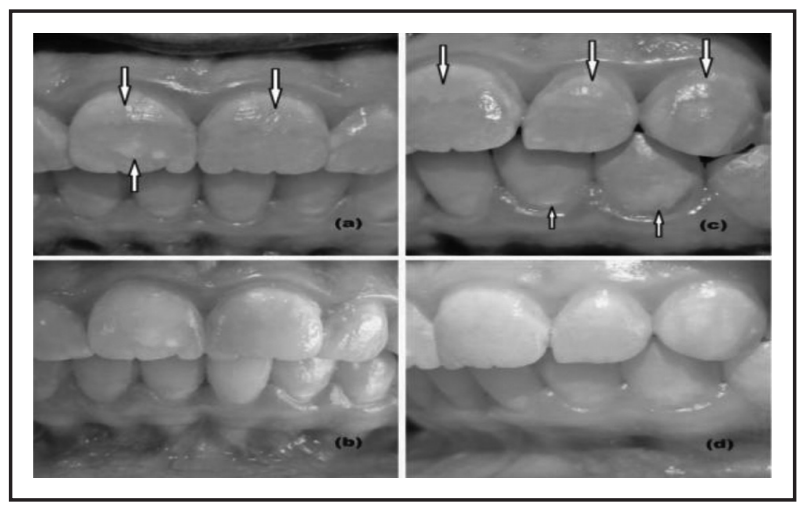

Fig. (3): Patient with white spot lesions (a and c) before tretment ( $b$ and d) after three months from Remin Pro forte treatment

\section{DISCUSSION}

Dental hard tissues are continuously undergoing cycles of demineralization as a result of $\mathrm{pH}$ drop of oral cavity and re-mineralization as a result of a $\mathrm{pH}$ rise leads to deposition of calcium, phosphate and fluoride. The progression of dental caries occurred when the demineralization exceeds remineralization (1). Dental caries results in the dissolution of apatite crystals and the loss of calcium, phosphate and other ions, which eventually leads to demineralization of the tooth substrate. The presence of clinically detectable, localized areas of enamel demineralization, observed as white spot lesions of different opacities, is a sign that the caries process has begun ${ }^{\left({ }^{12}\right)}$. The subsurface porosity caused by demineralization gives the lesion a milky appearance that can be found on the smooth surfaces of teeth which are called white spot lesion ${ }^{(4)}$.

Management of white spot lesions should involve methods of both preventing demineralization and encouraging the re-mineralization of existing lesions ${ }^{(13)}$. The current treatment for white spot lesion has shifted from the traditional drill and fills methodologies, to a less invasive approach that surrounds active monitoring of white spot lesion progression and re-mineralization using different re-mineralizing agents ${ }^{(7)}$. Re-mineralization simply is defined as the process whereby calcium and phosphate ions are supplied from an external source to the tooth thereby converting ion deposition into demineralised enamel crystals, producing net of minerals ${ }^{(1)}$. Biomimetic strategies for artificial enamel formation were produced for potentially repair enamel surface damage and increase the tooth re- mineralization ${ }^{(14)}$. Fluoride has a profound effect on the level of caries prevalence, but it is far from complete cure. Self-assembling peptide (P114) has shown great potential for natural repair of early caries lesions through emerging biomimetic re-mineralization properties $^{(7)}$. However, the favorable role of fluoride in preventing white spot lesion has been documented in the form of fluoride mouthwashes, fluoride gels, fluoride toothpastes, 
fluoride varnishes, fluoride in bonding agents, and fluoride in dental resin composite ${ }^{(5,15)}$.

The fluoride ion prevents dental caries, by modifying bacterial metabolism in dental plaque through inhibition of some enzymatic processes, by inhibiting production of acids by altering the composition of bacterial flora and/or the metabolic activity of microorganisms ${ }^{(5)}$. Fluoride is mainly attributed to precipitation of $\mathrm{CaF} 2$-like material on tooth surfaces, which is able to partially reduce tooth wear by subsequent erosive-abrasive challenges. This layer should behave as a physical barrier, preventing the contact of the acid with the underlying enamel, or as a mineral reservoir that is attacked by the erosive challenge, thus buffering the acids or promoting re-mineralization ${ }^{\left({ }^{(16)} \text {. According }\right.}$ to Lia et al ${ }^{(17)}$, it was shown that fluoride can induce fluorapatite (FA) or fluoridated hydroxyapatite (FHA) formation through reaction with HAP directly or promote the transformation of other calcium phosphate phases (such as octacalcium phosphate (OCP) and dicalcium phosphate dihydrate (DCPD)) to FA or FHA. The formation of FA or FHA can reduce the solubility of HAP.

Enamel is a highly mineralized acellular biological tissue lining the teeth. It is considered as the hardest and the most resistant tissue in the body, due to its contents of $95 \%$ inorganic material (calcium hydroxyapatite crystals). The function of enamel is to protect the dentin- pulp complex; therefore it was selected for this study ${ }^{(\mathbf{1 8})}$. The major inclusion that makes dental mineral much more acid soluble than hydroxyapatite or fluorapatite is the carbonate ion that substitutes for the phosphate ion in the crystal lattice, producing defects and calcium deficient regions. Approximately 1 out of 10 of the phosphate ions in enamel is replaced by carbonate and 1 out of 5 in dentine ${ }^{(19)}$. Therefore, re-mineralization of early enamel lesions is of great value to protect other dental tissues. Moreover, it was found that dentine re- mineralization is more difficult than enamel re-mineralization due to the abundant present of organic matrix in dentine ${ }^{(16)}$.
The penetrability of fluorides is limited and can only reach a few $\mu \mathrm{m}$ into enamel subsurface caries lesions. "Curodont Repair" offers monomeric selfassembling peptides (P11-4), which diffuses into the subsurface of WSL and self-assembles into 3D fibrillar scaffolds. The assembled P11-4 scaffold is capable of promoting de novo hydroxyapatite crystal nucleation and supports mineral crystal growth in a process of biomimetic mineralization. It is able to regenerate enamel using a process that is analogous to the enamel matrix during enamel formation ${ }^{(20)}$.

A self-assembling peptide (P11-4) treatment significantly increases net mineral gain due to a combined effect of increased mineral gain and inhibition of mineral loss ${ }^{(\mathbf{1})}$. It was concluded that it is useful in the modulation to induce hydroxyapatite nucleation, leading to the re-mineralization of white spot lesions through its diffusion into mineral loss and enhancement of hydroxyapatite precipitation (14). Its approach is to regenerate enamel based on the principle that monomers of this peptide congregate in three-dimensional network which simulate the enamel matrix. Novel hydroxyapatite crystals form on this matrix with the aid of calcium phosphate from the saliva, thus enable the regeneration ${ }^{(21)}$.

Remin Pro was suggested by the manufacture due to its content of hydroxyapatite (calcium and phosphate). The hydroxyapatite contained in Remin Pro fills superficial enamel lesions and the tiniest irregularities that arise from erosion. Remin Pro adheres to the tooth substance and protects the tooth against demineralization and erosion. The surface is noticeably smoothed and dentin tubules are superficially sealed. Furthermore, the smooth surface impairs the adhesion of bacterial plaque. Xylitol is a sugar which cannot be converted into harmful lactic acid by cariogenic bacteria and can reduce the harmful effects of these bacteria and the metabolic product lactic acid allowing the mouth to naturally re- mineralize damaged teeth. Scientific studies have confirmed the antimicrobial potential against oral microorganisms (especially against Streptococcus mutans) of ginger extracts 
and curcuma ${ }^{(22)}$. According to the manufacturer, Remin Pro® prevents tooth sensitivity by creating a protective layer on the teeth and inhibits bacterial plaque adhesion through smoothing the tooth surface.

This study was conducted on 45 white spot lesions detected clinically on labial surface. It was agreed with ${ }^{(23)}$ that there are significant morphological and chemical changes in teeth of patients of different age, which contribute to the planning of treatment materials that are optimized for different ages of patients. Patients of young age better in remineralization than old patients. On the other hand and according to an epidemiological study that $16 \%$ of adults have erosive lesions on the labial surfaces of their teeth which is more related to the excessive consumption intake of acidic beverages and food ${ }^{(24)}$. Therefore, patients that were enrolled in the study were of the age range between 20 - 30 years.

The ICDAS II scores represent a clinical method that relies on visual signs that represents manifestations of relatively advanced caries process ${ }^{(25)}$. The use of ICDAS-II to detect occlusal caries in the permanent and primary dentition has demonstrated reliable and accurate results ${ }^{(26-28)}$. Moreover, in epidemiological studies, ICDAS-II provided comparable data to those following the standard WHO criteria ${ }^{(29)}$. Others recommended ICDAS as a valuable method for detecting the enamel caries lesions for planning the individual re- mineralization therapy or for monitoring the caries pattern level ${ }^{(30)}$.

The chair side tests (CRT saliva buffer kit) assess the salivary conditions, which helps to determine the possible risk of caries. The $\mathrm{pH}$ strips kit is economical, time-effective and useful for measuring buffer capacity in resting saliva. From the CRT Buffer it is possible just to get ranking results and it is also possible to convert results from other tests into ranks of high, medium and low buffer capacity.

On comparing the Changes in the ICDAS II scores at baseline and after the three treatments, it was found that the mean percentage change in ICDAS II scores for all the three re-mineralizing agents used (Curodont repair, Lunos polier paste 2 in 1 and Remin Pro) improved with no statistical significant difference noted at baseline $(\mathrm{p}=0.54)$. However, at 3 months the difference between groups was statistically significant, since most of the cases in Remin Pro group recorded score 1 (66.6\%), while most of the cases in Curodont repair and Lunos polier paste 2 in 1 group scored $2(53.3 \%$ and $80 \%$ respectively). Score 0 recorded (20\%) for Remin Pro while (13.3\%) scored for Curodont repair, while, Lunos polier paste 2 in 1 recorded no 0 score. It was claimed by the manufacturer, that Remin Pro ${ }^{\circledR}$ protects the teeth by creating a protective layer on the teeth and inhibits bacterial plaque adhesion through smoothing the tooth surface. Those effects are consistent with ${ }^{(31)}$ who found that, Remin Pro forte as a re-mineralizing agent leads to regression of WSLs even in the short treatment period. Also, Korkut et al ${ }^{(32)}$ used the ICDAS as an assessment tool and found that the Remin Pro recorded better score than a paste contains $1100 \mathrm{ppm}$ fluoride. The reduction in the area of WSLs is not only important from the point of limiting caries lesion, but also from the esthetic point of view, especially in the anterior part of the dentition, where WSLs produce esthetic problems. This finding was attributed to; the effectiveness of $\mathrm{NaF}$ for reducing the area and increasing the mineral content of WSLs over time.

Concerning the effect of the three re-mineralizing agents on the saliva buffer, results showed that, the $\mathrm{pH}$ of group (A3: Remin Pro forte) showed higher increase followed by group (A1: Curodont repair) then group (A2: Lunos polier paste 2 in 1 . This could be related to the ginger, curcuma and xylitol found in Remin Pro that have an antibacterial effect against oral microorganisms (especially against Streptococcus mutans), and an anti-cariogenic effect also being described and reduce the amount of acids produced by these microorganisms as a result of carbohydrates fermentation ${ }^{(22,33)}$. On the other hand and according to Tantbirojn et al ${ }^{(24)}$, 
those results could be, due to the degree of saturation of Calcium and phosphate ions that differs from person to person, among various salivary glands, and with secretion rate, however; Remin Pro forte acts as a reservoir for calcium and phosphate ions as well as fluoride.

\section{CONCLUSIONS}

Under the limitation of this study, the following can be concluded:

1. All the tested materials have varying re-mineralization potential through Remin Pro forte was the most efficient.

2. Self assembling peptides (P11-4) seemed to resist the acid challenge.

3. All agents were clinically efficient in management of WSL in high risk patients.

\section{REFERENCES}

1. Nagarathana C, Sakunthala BK, and Naveena Preethi P. An Update on Current Remineralizing Agent. OHDM 2015; 14: $183-187$.

2. Raksha B, and Mithra HN. Overview on Re-mineralizing Agents. IJAR 2016; 6: 333-335.

3. Amaechi B.T. Re-mineralization Therapies for Initial Caries Lesions. Curr Oral Health Rep 2015; 2: 95-101.

4. AlShehri A and Kwon S.R. Etiology and management of white spot lesions. Prosthetics Restorative. J Multidiscipl Care, Decisions in Dentistry January 1, 2016: 10-19

5. Khoroushi M and Kachuie M. Prevention and treatment of white spot lesions in orthodontic patients. Contemp Clin Dent 2017; 8: 11-19.

6. Ceci M, Mirando M, Beltrami R, Chiesa M, Colombo M, and Poggio C. Effect of self-assembling peptide P11-4 on enamel erosion: AFM and SEM studies. Scanning Vol. 2016; 38: 344-351.

7. Brubaker L, Vinh A, Patel S, Solomon E, Amaechi B, and Noureldin A. Remineralization of early-enamel lesions using biomimetic regeneration combined with fluoridetoothpaste. Br Dent J 2015; 2-10.

8. Brunton P, Davies R, Burke J, Smith A, Aggeli A, Brookes $\mathrm{S}$ and Kirkham J. Treatment of early caries lesions using biomimetic self-assembling peptides - a clinical safety trial. Br Dent J 2013; 215: 1-6.

9. International Caries Detection and Assessment System Coordinating Committee. Rationale and Evidence for the International Caries Detection and Assessment System (ICDAS II) J Istanbul Univ Fac Dent 2015; 49:63-72.

10. Naif A. Almosa. Caries assessment in orthodontic patients. University of Gothenburg, Sweden 2014; 82: 267-274.

11. Trevisana T, Camposa A, Oliveira-juniora O, and Presotoa C. Clinical effectiveness of fluorescence, digital images and ICDAS for detecting occlusal caries. Rev Odontol UNESP 2017; 46: 109-115.

12. Cochrane NJ, Cai F, Huq NL, Burrow MF, Reynolds EC. New approaches to enhanced re-mineralization of tooth enamel. J Dent Res 2010; 89:1187-1197.

13. Karabekiroğlu S, Ünlü N, Küçükyilmaz E, Şener S, Botsali $\mathrm{M}$, and Malkoç S. Treatment of post-orthodontic white spot lesions with CPP-ACP paste: A three year follow up study. Dent Mater J 2017; 36: 791-797.

14. Takahashi F, Kurokawa H, Shibasaki S, Kawamoto R, Murayama R, and Miyazaki M. Ultrasonic assessment of the effects of self-assembling peptide scaffolds on preventing enamel demineralization. Acta Odontol Scand 2015; 74:142-147.

15. Arruda A, Behnan S, and Richter A. White-Spot Lesions in orthodontics: incidence and prevention, Contemporary Approach to Dental Caries, Dr. Ming-Yu Li (Ed.). 2012; 313- 332 .

16. Moron BM, Miyazaki SSH, Ito N, Wiegand A, Vilhena F, Buzalaf MAR, and Magalhaes AC. Impact of different fluoride concentrations and $\mathrm{pH}$ of dentifrices on tooth erosion/abrasion in vitro. Aust Dent J 2013; 58:106-111.

17. Lia X, Wanga J, Joinerb A, and Chang J. The remineralisation of enamel: a review of the literature. J Dent 2014; 42s1: s12-s20.

18. Medina S, Salazar L, Mejía C and Moreno F. In vitro behavior of the dentin and enamel calcium hydroxyapatite in human premolars subjected to high temperatures. DYNA 2016; 83: 34-41.

19. Featherstone JDB. Dental caries: a dynamic disease process. Aust Dent J 2008; 53: 286-291.

20. Kirkham J, Firth A, and Vernals D. Self-assembling peptide scaffolds promote enamel remineralization. J Dent Res 2007; 86: 426-430. 
21. Jayasudha, Baswaraj, Navin H.K, and Prasanna K.B. Enamel Regeneration - Current Progress and Challenges. J Clin Diagn Res 2014; 8: ZE06-ZE09.

22. VOCO. http://www.hambaarst.ee/share/file/pdf/voco/Remin_ Pro.pdf. 2016.

23. Kunin A, Evdokimova A, and Moiseeva N. Age-related differences of tooth enamel morphochemistry in health and dental caries. EPMA J 2015; 6: 3-10.

24. Tantbirojn D, Huang A, Ericson MD, and Poolthong S. Change in surface hardness of enamel by a cola drink and a CPP-ACP paste. J Dent 2008; 36:74-79.

25. Diniz MB, Rodrigues JA, Hug I, Cordeiro Rde C, Lussi A. Reproducibility and accuracy of the ICDAS-II for occlusal caries detection. Community Dent Oral Epidemiol. 2009; 37: 399-404.

26. Jablonski-Momeni A, Stachniss V, Ricketts DN, HeinzelGutenbrunner M, Pieper K. Reproducibility and accuracy of the ICDAS-II for detection of occlusal caries in vitro. Caries Res 2008; 42: 79-87.

27. Shoaib L, Deery C, Ricketts DN, Nugent ZJ. Validity and reproducibility of ICDAS II in primary teeth. Caries Res 2009; 43: 442-448.

28. Braga MM, Martignon S, Ekstrand KR, Ricketts DN, Imparato JC, Mendes FM. Parameters associated with active caries lesions assessed by two different visual scoring systems on occlusal surfaces of primary molars a multilevel approach. Community Dent Oral Epidemiol 2010; 38: 549-558.

29. Braga MM, Oliveira LB, Bonini GA, Bonecker M, Mendes FM. Feasibility of the International Caries Detection and Assessment System (ICDAS-II) in epidemiological surveys and comparability with standard World Health Organization criteria. Caries Res 2009; 43: 245-249.

30. Honkala E, Runne R, Honkala S, Olak J, Vahlberg T, Saag M, and Mäkinen K. Clinical Study, Measuring Dental Caries in the Mixed Dentition by ICDAS. Int J Dent 2015; 15: 13-21.

31. Ebrahimi M, Mehrabkhani M, Ahrari F, I Parisay I, and Jahantigh M. The effects of three remineralizing agents on regression of white spot lesions in children: A two-week, single-blind, randomized clinical trial. J Clin Exp Dent 2017; 9: e641-8.

32. Korkut B, Korkut D, Yanikoglu F, Tagtekin D. Clinical assessment of demineralization and remineralization surrounding orthodontic brackets with FluoreCam. Asian Pac J Trop Biomed 2017; 7: 373-377.

33. Sandhu K, Gupta N, Gupta P, Arora V, and Mehta N. Caries Protective Foods: A Futurist Perspective IJHS 2014; 1:21-25. 